Voltaire de Freitas Michel ${ }^{1}$

Marc Antoni Deitos ${ }^{1}$

\title{
TEORIAS DA JUSTIÇA E SAÚDE PÚBLICA
}

Theories of justice and public health

${ }^{1}$ IMED - Faculdade Meridional. Porto Alegre/RS, Brasil.

Correspondência: Voltaire de Freitas Michel. E-mail: voltairemichel@hotmail.com

Recebido: 30/08/2017. Revisado: 11/01/2018. Nova revisão: 26/03/2018. Aprovado: 15/05/2018. 


\section{RESUMO}

Na primeira parte, este artigo procura identificar as principais soluções propostas pelas teorias da justiça contemporâneas para a distribuição de bens escassos. Na segunda parte do trabalho, busca-se aplicá-las a modelos ideais de sistemas de saúde pública. Em outras palavras, o trabalho investiga critérios de justiça distributiva no fornecimento de serviços de saúde (tratamentos ou medicamentos), por meio de prestações, pelo Estado, para qualquer indivíduo, independentemente de sua condição financeira ou da causa da doença (involuntária ou provocada). Esses dois elementos da delimitação não são absolutamente moralmente neutros, porém, para efeitos didáticos, estão isolados e são desconsiderados na discussão que se propõe. Conclui-se que, por detrás de opções fundamentais a respeito dos limites e da distribuição de serviços de saúde, encontra-se um critério de justiça perfeitamente identificável e, por vezes, inconciliável com outras opções. O problema do trabalho consiste na delimitação do que é o justo na prestação dos tratamentos a partir do ponto de vista de diferentes concepções de justiça. A metodologia empregada é descritiva do estado atual da discussão a respeito das teorias da justiça, seguida de uma aplicação dialética ao exame de modelos ideais de sistemas de saúde.

\section{Palavras-chave}

Saúde Pública; Serviços de Saúde; Teorias da Justiça.

\section{ABSTRACT}

In the first part, this article identifies the main solutions proposed by contemporary theories of justice for the distribution of scarce goods. In the second part of the paper, it applies them to the ideal models of public health systems. In other words, the paper investigates criteria of distributive justice in the provision of health services (treatments or medications), by means of benefits, by the State, to any individual, regardless of their financial condition or the cause of the illness (involuntary or provoked). These two elements of delimitation are not absolutely morally neutral, but for didactic purposes, they are isolated and disregarded in the discussion that is proposed. The conclusion is that, behind fundamental choices regarding the limits and distribution of health services, a criterion of justice is perfectly identifiable and sometimes irreconcilable with other options. The problem of this paper consists in the delimitation of what is fair in the provision of treatments from the point of view of different conceptions of justice. The methodology used is descriptive of the current state of the discussion about theories of justice, followed by a dialectical application to the examination of ideal models of health systems.

\section{Keywords}

Health Services; Public Health; Theories of Justice. 


\section{Introdução}

Talvez um dos aspectos mais complexos da vida social seja o modo como lidamos com a saúde e a doença. A primeira variável que torna o problema particularmente complexo é a pluralidade de causas: a doença, antítese da saúde, pode decorrer do mero acaso (causas genéticas ou pura má sorte); de decisões individuais imprudentes (estilos de vida arriscados); ou, ainda, da ação de terceiros (por exemplo, a sujeição de trabalhadores a condições insalubres de trabalho). A deterioração da saúde, portanto, é por excelência um fenômeno pluricausal. Em alguns casos, faz sentido tratá-la como um sinistro previsível; em outros, é puro resultado de ações deliberadas do adoecido ou de terceiros.

No outro extremo da equação, pergunta-se: como recuperar a saúde? Quem está adoecido tem direito a um tratamento pago por terceiros, diretamente ou pelo Estado? Quem tem condições de ajudar alguém a recuperar a saúde pode prestar esse serviço mediante remuneração ou tem o dever de prestar o tratamento por humanidade? Aqueles que deliberadamente deterioraram a própria saúde têm o mesmo direito a um atendimento médico que os demais? E está na esfera de disponibilidade do adoecido a recusa ao tratamento? Faz sentido, econômica ou moralmente, tratar um doente irrecuperável? Entre gastar com um tratamento para alguém desenganado e investir em saúde básica, que potencialmente pode melhorar a qualidade de vida de outras pessoas, qual é a melhor decisão? Qual é a decisão justa ou qual é a decisão moralmente correta?

A primeira resposta a ser descartada é a meramente dogmática. De nada adianta afirmar que é justo o tratamento universal e gratuito, se a estrutura que provê esse atendimento for fruto de uma decisão política circunstancial. Quer dizer, a mera busca de apoio na Constituição é uma resposta insuficiente e superficial, pois basta retroceder e observar a história constitucional brasileira para perceber que as opções fundamentais do Direito Constitucional são móveis e flexíveis, transformando-se ao sabor das conveniências políticas. Em resumo: amparar a resposta sobre o que é o justo no tema da saúde pública apenas no texto constitucional significa correr o risco de ter uma resposta efêmera e substituível, dependente da quadratura política. A mera referência ao texto da Constituição Federal é pouco para um discurso a respeito da justiça. "Está na Constituição" não significa, preliminarmente, que uma decisão política é moralmente imune à crítica; além disso, a previsão genérica de um direito à saúde na Carta Magna não provê os pormenores da satisfação desse direito, espaço para a configuração de políticas públicas que se determinarão num sentido mais ou menos abrangente.

A expressão "ter direito à saúde" pode ser interpretada de muitas formas. De forma mais ampla, e talvez inútil para o discurso jurídico, pode-se interpretar a fórmula como um desejo ou uma aspiração a que todos tenham uma vida saudável. Nesse plano abstrato, o "direito à saúde" ainda não emerge em todos os seus 
pormenores - ou, melhor dizendo, em que medida esse direito determinará a alguém ou a alguma instituição um dever de agir. Mais restritamente, o "direito à saúde" pode ser interpretado como um direito à prestação de um serviço de saúde por meio de tratamentos ou medicamentos, um direito a uma prestação material específica do Estado, exigível por alguém; indo-se um pouco além, a expressão também pode significar que há um direito da sociedade a ações públicas em geral que busquem ou favoreçam a saúde, tais como saneamento básico, fornecimento de água potável, combate a vetores de doenças etc. Nesse cenário, uma visão extremamente paternalista de saúde pública negaria tratamento, por exemplo, a quem voluntariamente tivesse provocado a doença (entenda-se "paternalista" aqui no sentido de pai que nega uma vantagem ao filho que não fez por merecê-la, e não no sentido mais comum de tutela do indivíduo pelo Estado).

Quem precisa de saúde, em primeiro lugar, evitará a doença; caso perca a saúde, se tiver os recursos, mas não tiver alguém que proveja os remédios ou tratamentos, comprará os serviços. Quem, por outro lado, necessitar dos serviços ou medicamentes e não tiver condições de comprá-los, precisará de um terceiro que os proveja - um amigo, uma instituição ou o Estado -; ou seja, dependerá da misericórdia, e assim foi durante boa parte da história da humanidade, ou dependerá de uma ação do Estado. Quanto menos misericórdia, maior a demanda por ações públicas, individuais ou genéricas. Em interessante observação em sua obra singular a respeito da justiça e dos critérios para distribuição de bens, Michael Walzer ${ }^{1}$ acentuou que, durante boa parte da história da humanidade, a doença era um problema privado, e a salvação da alma, uma alta questão de indagação pública (lembre-se, aqui, do belicoso ambiente europeu na época das guerras religiosas, que acabaram por refundar o Estado Moderno). Hoje, ao contrário, a salvação das almas é um tema sobretudo privado, ao passo que a salvação do corpo tornou-se o tema central das políticas públicas na maioria das democracias ocidentais: é no que mais se gasta, são os maiores orçamentos dos países que oferecem saúde universal.

A saúde não é apenas um problema distributivo em sentido estrito. Em alguns aspectos, $o$ atendimento à saúde implica uma intervenção na relação entre entes privados, bem além da relação entre indivíduos e o Estado. Ilustre-se esta afirmação com a profunda intervenção da legislação reguladora nos contratos de seguro de saúde ou nas relações entre empregadores e empregados. O próprio direito do trabalho e o direito do consumidor já reconhecem as diferenças de fato entre os dois polos da relação, genericamente falando; a variável da saúde apenas desequilibraria a relação em favor de quem teve a saúde prejudicada ou arriscada pela parte mais poderosa. Ainda aqui, embora não haja a distribuição de um serviço propriamente dito, não se pode descartar que há uma redistribuição representada

${ }^{1}$ WALZER, Michael. Spheres of justice: a defense of pluralism and equality. New York: Oxford University Press, 1983. 
pela maior proteção jurídica outorgada ao segurado ou ao consumidor. De qualquer forma, o que se diz sobre uma ação de distribuição de serviços de saúde, em sentido mais restrito, seria aplicável ao reequilíbrio das relações entre partes mais e menos poderosas.

Diante de um cenário de recursos escassos e demanda contínua e crescente, o problema do modo de distribuição desses recursos torna-se central. A demanda é contínua, principalmente pelo desenvolvimento das técnicas, cada vez mais sofisticadas e inspiradoras de esperança de cura, mas também pelo contínuo ajuizamento de ações em que se postulam tratamentos e medicamentos em face do Estado. De todas as questões sugeridas nos parágrafos anteriores, a mais importante sob o aspecto distribucional é a delimitação do que é o justo na prestação dos tratamentos, que consiste no problema deste trabalho. Com essa delimitação, e isolando todas as demais variáveis, está definido o objetivo deste trabalho: identificar as principais soluções propostas pelas teorias da justiça contemporâneas para a distribuição de bens escassos, na primeira parte do trabalho; e, na segunda parte, aplicá-las a modelos ideais de sistemas de saúde pública. Em outras palavras, o trabalho busca critérios de justiça distributiva no fornecimento de serviços de saúde (tratamentos ou medicamentos), que se dá por meio de prestações pelo Estado para qualquer indivíduo, independentemente de sua condição financeira ou da causa da doença (involuntária ou provocada). Esses dois elementos da delimitação não são absolutamente moralmente neutros, porém, para efeitos didáticos, estão isolados e são desconsiderados na discussão que se propõe. A metodologia empregada é descritiva do estado atual da discussão a respeito das teorias da justiça, seguida de uma aplicação dialética ao exame de modelos ideais de sistemas de saúde.

\section{Panorama das teorias da justiça: critérios para distribuição dos bens}

Mais importante do que a apresentação teórica das mais diversas teorias da justiça contemporâneas é a delimitação clara de seus critérios para a distribuição dos bens. Por isso, nesta seção do artigo, serão apresentados, sucessivamente, os critérios de justiça utilitarista, igualitarista (teleológico e deontológico), prioritarista e libertarista.

\section{0 critério de justiça utilitarista}

Jeremy Waldron ${ }^{2}$ inicia sua apresentação das mais diversas teorias da justiça estabelecendo uma distinção entre as teorias que expressam uma concepção de bem específico e as teorias que, ao contrário, têm a pretensão de conjugar, de alguma forma, concepções plurais sobre o bem. Nesta última categoria enquadraríamos,

${ }^{2}$ WALDRON, Jeremy. Law and disagreement. New York: Oxford University Press, 1999. 
por exemplo, a teoria da justiça de John Rawls ${ }^{3}$, com sua intenção de promover uma acomodação de várias concepções divergentes de bem; já na primeira categoria, ingressariam as teorias que, ao contrário, não têm a vocação para o pluralismo e representam, antes, uma opção certa e determinada por um certo bem.

A teoria utilitarista é um dos exemplos de teoria da justiça polarizada pela ideia de bem, ainda que a ser alcançado por meio de um cálculo interessado. Em síntese, é moral, e da mesma forma, justa, a decisão que produzir um melhor resultado, que aproximar a situação de fato de um objetivo declarado. $\mathrm{O}$ foco da moralidade utilitária está nas consequências da ação em vista do objetivo almejado, e não na ação em si, que pode até mesmo ser moralmente condenável por outros critérios de apreciação. A teoria utilitarista conheceu uma longa evolução, em que versões mais modernas deslocaram o foco da ação em si, da análise de sua moralidade ou justiça, para a anamnese das regras que orientam o comportamento humano em um sentido ou outro. Nesse novo cenário, o discurso muda: não é a ação, mas a regra que pode conduzir a um resultado mais útil ou não ${ }^{4}$.

Para ilustrar a lógica do utilitarismo, Thomas Nagel ${ }^{5}$ sugere uma reflexão a respeito da utilidade de uma ação a partir do exemplo dos dois filhos, que pode ser assim sumarizado: um casal tem dois filhos, um saudável e outro que precisa de muita atenção médica. O dilema é a família mudar-se para o subúrbio, onde o saudável poderá brincar na rua e ter uma vida melhor, ou para a cidade, onde todos morarão enclausurados, porém mais próximos do atendimento médico para o filho doente.

Derek Parfit ${ }^{6}$ organiza o problema inicial com o seguinte esquema, adaptado para as finalidades deste trabalho (Tabela 1).

Tabela 1. Nagel e a caso dos irmãos

\begin{tabular}{lcc}
\hline & $\begin{array}{c}\text { Nível de benefício ou felicidade } \\
\text { alcançado pela criança saudável }\end{array}$ & $\begin{array}{c}\text { Nível de benefício ou felicidade } \\
\text { alcançado pela criança doente }\end{array}$ \\
\hline Mudar para a cidade & 20 & 10 \\
Mudar para o subúrbio & 25 & 9 \\
\hline
\end{tabular}

${ }^{3}$ RAWLS, John. Uma teoria da justiça. São Paulo: Martins Fontes, 2002.

${ }^{4}$ A respeito dos argumentos pró e contra o utilitarismo, ver SMART, J.C.C.; WILLIAMS, Bernard. Utilitarianism: for \& against. United Kingdom: Cambridge University Press, 1973; e KYMLICKA, Will. Filosofia política contemporânea. São Paulo: Martins Ed., 2006. p. 11 e ss.

${ }^{5}$ NAGEL, Thomas. Mortal Question. Cambridge: Cambridge University Press, 1979, p. 123-4 apud PARFIT, Derek. Equality and priority. Ratio 10, p. 201-221, Dec. 1997.

${ }^{6}$ Id. Ibid. 
Segundo Derek Parfit ${ }^{7}$,um utilitarista escolheria, entre as duas soluções, a mudança para o subúrbio, pois ali o menino saudável seria muito, mas muito mais feliz (índice 25), e o menino doente, apenas um pouco mais triste (índice 9), totalizando um índice de felicidade de 34. A mudança para a cidade, que tornaria o menino doente um pouco mais feliz (índice 10), não faria o menino saudável muito feliz, com a felicidade combinada de ambos alcançando o índice de 30. Neste cenário, o moral e justo seria a opção pelo subúrbio, não obstante a crueldade com o menino doente.

O critério utilitarista de justiça enfrenta muitas objeções, e a mais evidente é a da incomensurabilidade dos índices. Certamente, o cálculo no exemplo anterior depende sobretudo da precisão dos índices; qualquer alteração ou variação poderá indicar uma resposta moralmente errada ou injusta. Além disso, a deliberação do objetivo pode ser também nitidamente arbitrária ou flexível, adaptável a diferentes contextos $^{8}$.

\section{0 critério de justiça igualitarista}

Segundo o critério igualitarista, o justo ou o desejável é um resultado em que todos tenham acesso ao mesmo serviço. $\mathrm{O}$ ideal a ser alcançado é a igualdade na distribuição dos bens. Num molde mais radical, segundo este critério, qualquer desigualdade é condenável e exprime uma situação pior, sob o ponto de vista da justiça, do que um cenário de total igualdade.

O primeiro argumento a favor do igualitarismo é de natureza eminentemente econômica, qual seja, o princípio da diminuição da utilidade marginal. Segundo este princípio, a partir de uma certa quantidade de riqueza - ou de unidades ou de serviços -, as quantidades adicionais não geram a mesma satisfação promovida pelas iniciais. Por isso, a simples distribuição igual de todos os recursos produziria um maior nível de aproveitamento e satisfação desses recursos ${ }^{9}$.

Segundo Harry Frankfurt ${ }^{10}$, no entanto, o princípio da diminuição da utilidade marginal nada mais é do que uma generalização psicológica que cederia diante da viabilidade de acumulação por meio do dinheiro, da versatilidade da pecúnia ${ }^{11}$. Para ilustrar esse argumento contra o igualitarismo, Frankfurt usa a seguinte ilustração: suponha que o custo de uma porção de pipocas seja o mesmo de uma certa quantidade de manteiga para melhorá-la; suponha, ainda, que determinado consumidor

\footnotetext{
${ }^{7}$ PARFIT, Derek. op. cit.

${ }^{8}$ ALEXANDER, Gregory; PEÑALVER, Eduardo M. An introduction to property theory. New York: Cambridge University Press, 2012. p. 29.

${ }^{9}$ FRANKFURT, Harry G. Equality as a moral ideal. In: FRANKFURT, Harry G. The importance of what we care about. New York: Cambridge University Press, 1988. p. 134-158.

${ }^{10}$ Id. Ibid.

${ }^{11}$ Id. Ibid.
} 
extraia pouca satisfação de uma porção de pipoca sem manteiga, mas ainda assim prefira pipoca a comer apenas manteiga; se ele tiver recursos para comprar apenas a pipoca ou a manteiga, comprará a pipoca; admita-se que ele aumente sua renda, permitindo-lhe comprar pipoca e manteiga; neste caso, a satisfação obtida com a pipoca e a manteiga ultrapassará com folga a satisfação obtida isoladamente com o consumo da pipoca ou da manteiga. Em resumo, um incremento de unidades de riqueza sobre um patamar já atingido poderá, no caso concreto, multiplicar a satisfação, ao invés de diminuir a importância marginal.

Outra refutação ao argumento dá-se no cenário em que a distribuição igualitária geraria efeitos desastrosos, com a diminuição da utilidade agregada. Num cenário de escassez, uma distribuição igualitária pode ser moralmente inaceitável. Por exemplo, suponha que haja 40 unidades para distribuir entre dez pessoas e que o nível aceitável de sobrevivência exija pelo menos cinco unidades. No caso concreto, a distribuição igualitária atribuiria a cada pessoa apenas quatro unidades, quantidade insuficiente para a sobrevivência; assim, todos as dez pereceriam. Ao contrário, se fossem atribuídas cinco unidades a cada uma das pessoas, pelo menos oito sobreviveriam. O resultado da primeira distribuição igualitária parece nitidamente imoral e desastroso ${ }^{12}$.

Outro argumento a favor do igualitarismo seria uma intuição moral de que é errado uns terem mais do que outros. Este argumento sinaliza para o desconforto psicológico da ideia de desequilíbrio. Da mesma forma, Frankfurt ${ }^{13}$ o rechaça, contra-argumentando que, se esse desconforto fosse real e justificativo do igualitarismo, teria que estar presente também quando se comparam, por exemplo, as condições da classe média alta com pessoas riquíssimas. Neste exemplo, normalmente não há desconforto. Logo, o desconforto, segundo Frankfurt ${ }^{14}$, que defende uma visão prioritarista, está no fato de alguns não terem o suficiente, e não no fato de alguns terem mais do que outros. A intuição moral direciona para que haja uma suficiência para os que têm menos, e não para uma igualdade absoluta.

Segundo Derek Parfit ${ }^{15}$, um defensor do igualitarismo reputaria mais justa uma melhor distribuição, ainda que os benefícios fossem globalmente menores. Retomando a Tabela 1, que ilustra o problema dos dois irmãos proposto por Thomas Nagel $^{16}$ : um igualitarista escolheria a primeira linha, pois no cenário de 20/10 há mais igualdade do que no cenário 25/9, ainda que o menino doente seja prejudicado. Segundo Parfit ${ }^{17}$, é possível um detalhamento a respeito da posição igualitarista, distinguindo entre os teleological egalitarians (igualitaristas teleológicos) e os

\footnotetext{
${ }^{12}$ FRANKFURT, Harry G. op. cit.

${ }^{13}$ Id. Ibid.

${ }^{14}$ Id. Ibid.

${ }^{15}$ PARFIT, Derek. op. cit.

${ }^{16}$ Id. Ibid.

${ }^{17}$ Id. Ibid.
} 
deontological egalitarians (igualitaristas deontológicos). Um teleological egalitarian (ou "telic egalitarian") consideraria ruim que algumas pessoas estivessem em uma posição pior do que outras. A única variável em causa seria a igualdade, independentemente da utilidade do esquema de distribuição. Por outro lado, ainda no campo igualitarista, os os "deontological egalitarians" (pluralists), de alguma forma, combinariam o objetivo de igualdade com a utilidade resultante da distribuição, numa certa proporção. Veja-se o Quadro 1, adaptado do quadro original apresentado por Parfit ${ }^{18}$ :

Quadro 1. Exemplo dos mundos paralelos

\begin{tabular}{|ll|}
\hline Situação 1 & Todos com 150 \\
\hline Situação 2 & Metade com 199, metade com 200 \\
Situação 3 & Metade com 101, metade com 200 \\
\hline
\end{tabular}

Elaboração própria.

A situação 1 é mais desejável para os teleological egalitarians, pois ali a igualdade é total. Para um utilitarista, a melhor situação seria a 2, pois apresenta o maior número de unidades somado. Por fim, para um deontological egalitarian, é menos precisa a definição, porque há que se estabelecer uma proporção entre os benefícios da igualdade e da utilidade. Um exemplo correto da posição igualitarista deontológica seria o princípio da diferença na Teoria da Justiça de John Rawls ${ }^{19}$, segundo a qual as desigualdades são úteis quando resultam em benefícios para todos e, em particular, para os membros menos privilegiados da sociedade.

Segundo José Nedel,

Na perspectiva de Rawls, há desigualdades úteis, decorrentes que são, em parte, da necessidade de conceder incentivos a determinadas pessoas para que realizem certas atividades ou desempenhem determinados papéis, o que nem todos são capazes de realizar com igual perfeição. Tais desigualdades, não necessárias para preenchimento de cargos para os quais todos seriam aptos, se justificam, na hipótese de contribuírem para melhorar a posição do grupo em pior situação, quando sem elas tal grupo permaneceria em estado ainda mais lamentável ${ }^{20}$.

${ }^{18}$ PARFIT, Derek. op. cit.

${ }^{19}$ MICHEL, Voltaire F. O princípio da diferença e o kantismo na teoria da justiça de John Rawls. Tese (Doutorado) - Faculdade de Direito, Universidade Federal do Rio Grande do Sul, Porto Alegre, 2007.

${ }^{20}$ NEDEL, José. A teoria ético-política de John Rawls: uma tentativa de integração de liberdade e igualdade. Porto Alegre: EDIPUCRS, 2000. p. 67. 
Rawls poderia ser enquadrado na categoria do igualitarismo deontológico: a regra é a igualdade, tolerando-se a desigualdade quando a distribuição desigual dos bens favorece o escalão menos favorecido.

Para ilustrar a posição dos igualitários teleológicos, Parfit ${ }^{21}$ emprega a ilustração do "mundo dividido": as duas metades do mundo são povoadas por grupos que não têm consciência da existência da outra metade (por exemplo, dois continentes antes das navegações, que não faziam parte da mesma comunidade). A distribuição dos bens pode se desenhar da seguinte forma: (i) metade tem 100, metade tem 200; e (ii) todos têm 145.

Para esses teleological egalitarians, a primeira situação é em si mesma pior, ainda que as metades não integrem a mesma comunidade, porque há uma desigualdade entre os grupos. Para os igualitários deontológicos, no entanto, a igualdade é um objetivo por razões morais, mas exige uma comparação; a desigualdade é injusta, e não má, e sempre envolve alguma ação executada de forma injusta. O que é injusto não é o estado de coisas resultante, mas o modo pelo qual ele foi produzido. Se nada pode ser feito, não há injustiça. No caso do "mundo dividido", não haveria lugar para caracterizar a situação como injusta. No mesmo sentido, a distribuição de talentos inatos não implica uma relação de injustiça: inteligência, beleza, força, talentos inatos poderão resultar situações privilegiadas numa sociedade, que não são injustas sob esse ponto de vista ${ }^{22}$. São injustas, segundo os deontological, apenas as desigualdades que resultam de ações, ou apenas aquelas que são intencionalmente produzidas.

Certamente a objeção mais desconfortável ao telic egalitarianism é a do nivelamento (Levelling Down Objection): se alguns têm mais e outros menos, seria desejável acabar com as vantagens dos demais para alcançar um estado de igualdade, ainda que ninguém se beneficie disso ${ }^{23}$. Já o deontological egalitarianism não está exposto a essa objeção, pois, ao menos segundo $R_{a w l}{ }^{24}$, há uma razão para manter a desigualdade: apenas porque essa ação beneficia as pessoas que estão na base.

Novamente, o exemplo do mundo dividido (exemplo dos dois continentes antes das navegações que não fazem parte da mesma comunidade): (i) metade tem 100, metade tem 200; e (ii) todos têm 145. Para os deontic egalitarians, a desigualdade na primeira situação não foi produzida por ninguém, então a questão da justiça não se coloca. Para os telic egalitarians, a desigualdade dessa situação é em si mesma ruim.

\footnotetext{
${ }^{21}$ PARFIT, Derek. op. cit.

${ }^{22}$ Para Rawls (Uma teoria da justiça, cit.), a justiça as fairness lida justamente com esses resultados decorrentes das diferenças, das desigualdades imerecidas. Ver Nedel, fl. 68, sobre a "loteria natural". A respeito da controvérsia na tradução das palavras justice e fairness, ver DALRYMPLE, Theodore. Fairly just. In: DALRYMPLE, Theodore. Farewell fear. Nashville: New English Review Press, 2012.

${ }^{23}$ FRANKFURT, Harry G. op. cit.

${ }^{24}$ RAWLS, John. op. cit.
} 


\section{0 critério de justiça prioritarista}

Voltando ao caso dos dois irmãos, Nagel ${ }^{25}$ diz que a prioridade é beneficiar a criança doente, aludindo à igualdade. Mas, segundo Derek Parfit $t^{26}$, suas razões são, na verdade, polarizadas pela ideia de prioridade: antes de atender ao supérfluo ou ao abundante, a justiça determinaria que se satisfizessem as necessidades imediatas dos mais prejudicados. Tal o sentido, segundo Parfit ${ }^{27}$, do prioritarismo: deve-se beneficiar com prioridade as pessoas que tiverem mais necessidade.

Segundo Parfit, o prioritarismo não é uma expressão do igualitarismo, pois vê o problema da justiça de forma radicalmente diferente. Para tanto, Parfit ${ }^{28}$ ilustra com a imagem do ar rarefeito nas montanhas, e a relação que se pode estabelecer com quem está no nível do mar ou no topo. Conforme Parfit ${ }^{29}$, para um prioritarian (prioritarista), não se estabelece aqui uma relação de injustiça ou desigualdade; o necessário é suprir o oxigênio para quem está na região de ar rarefeito, até o nível necessário para a sobrevivência. Ao contrário, um igualitarista estabeleceria imediatamente uma relação entre os dois polos, para então verificar se a distribuição de ar é justa ou injusta. No extremo, um egalitarian poderia afirmar que "reduzir" o oxigênio dos que se encontram no nível do mar conduziria a um estado de coisas mais justo, moralmente preferível ${ }^{30}$. Egalitarians estão preocupados com a posição relativa; prioritarians estão preocupados com a posição absoluta. Nesse cenário, prioritarians não estão expostos à objeção do nivelamento, fatal para o critério igualitário (levelling down objection).

A posição prioritarista, no entanto, enfrenta outras objeções. A primeira delas é a da ineficiência. A ideia de que a solução da prioridade pode ser ineficiente pode ser ilustrada pelo tratamento conferido aos soldados feridos no campo de batalha: qual é a extensão do tratamento médico que deve ser destinado a eles? Segundo os Wolffe De-Shalit ${ }^{31}$, os soldados feridos podem ser classificados em três categorias: (a) o que vai morrer ou é muito custoso salvar; (b) o que, com pouca ajuda médica, pode ser salvo e voltar para a linha de batalha: (c) o que está praticamente bem, só precisa de atendimento médico mínimo. Pelo argumento baseado na eficiência, utilitarista, polarizado pelo interesse de vencer a batalha, só faria sentido gastar com (b); seria um desperdício gastar com (a), assim como com (c). Segundo o argumento prioritarista, faz sentido gastar com o (a), pois ele tem a maior necessidade ${ }^{32}$.

\footnotetext{
${ }^{25}$ PARFIT, Derek. op. cit.

${ }^{26}$ Id. Ibid.

${ }^{27}$ Id. Ibid.

${ }^{28}$ Id. Ibid.

${ }^{29}$ Id. Ibid.

${ }^{30}$ Id. Ibid.

${ }^{31}$ WOLFF, Jonathan; DE-SHALIT, Avner. Priority to the least advantaged. In: KYMLICKA, Will; MILLER, David (Eds.). Disadvantage. New York: Oxford University Press, 2007. p. 155-166.

${ }^{32}$ Id. Ibid.
} 
De acordo com Wolf e De-Shalit ${ }^{33}$, o argumento contrário ao prioritarismo pode ser refutado. Segundo eles, a prioridade tem um aspecto moral, e o argumento da ineficiência é limitado ao aspecto econômico e se prende ao cenário mais amplo; na verdade, o pouco que se pode fazer pelo muito necessitado faz muita diferença. A esse respeito, os autores transcrevem o argumento de Pogge.

[...] a pobreza mundial surge como uma tarefa esmagadora para a qual nós, enquanto indivíduos, não podemos contribuir significativamente. Fazemos uma contribuição para ajudar após um terremoto e descobrimos que, dois anos depois, a cidade prejudicada foi largamente reconstruída, com nossa ajuda. Fazemos uma contribuição para mitigar a pobreza e descobrimos que, dois anos depois, o número de pessoas que vivem e morrem na extrema pobreza ainda é incrivelmente alto. A primeira contribuição parece significativa porque pensamos na tarefa como limitada a um desastre - ao invés de incluir os efeitos de tragédias naturais, digamos. A segunda contribuição parece inútil. Mas tais aparências surgem de nossas categorias convencionais de classificação. Ao enxergar os pobres do mundo como uma imensa massa homogênea, desconsideramos que salvar dez crianças de morrer dolorosamente de fome é fazer uma diferença de fato, toda a diferença para essas crianças, e que essa diferença é bastante significativa mesmo quando muitas outras crianças continuam com fome ${ }^{34}$.

Outro argumento que aparentemente colide com a ideia da prioridade é o argumento da equidade. $\mathrm{O}$ que dizer para os que pagam impostos e nada recebem em contrapartida? Certamente, os que tem alguma coisa pagarão os tributos e financiarão a distribuição; e certamente os pagadores não são os recebedores. Parece que não há equidade, tratamento igual. Segundo Wolffe De-Shalit ${ }^{35}$, a objeção é razoável e implica que os pagadores também recebam uma vantagem para que adiram à ideia distributiva, e também para que não haja alienação de grupos (todos recebem um vale-alimentação, mas os pobres, mais).

\footnotetext{
${ }^{33}$ WOLFF, Jonathan; DE-SHALIT, Avner. op. cit.

${ }^{34}$ POGGE, Thomas. World Poverty and Human Rights. Cambridge: Polity 2002, p. 8, apud WOLFF, Jonathan; DE-SHALIT, Avner. op. cit., p. 157. No original: “[...] world poverty appears as one overwhelming task to which we, as individuals, cannot meaningfully contribute. One makes a disaster relief contribution after an earthquake and finds that, two years later, the damaged city has been largely rebuilt, with our help. One makes a contribution to poverty relief and finds that, two years later, the number of people living and dying in extreme poverty is still unimaginable large. The former contribution seems meaningful because we think of the task as limit to one disaster. - rather than including the effects of natural disasters, say. The latter contribution appears pointless. But such appearances arise from our conventional sorting categories. Seeing the global poor as not vast homogeneous mass, we overlook that saving ten children from a painful death by hunger does make a real difference, all the difference for these children, and that this difference is quite significant even, when many other children remain hungry."

${ }^{35}$ WOLFF, Jonathan; DE-SHALIT, Avner. op. cit.
} 
Outra objeção à ideia de prioridade é como classificá-la: a necessidade deve ser considerada em sentido global ou setorial? Em outras palavras, o que será determinante para o reconhecimento de alguém como necessitado: deficiências de educação, pobreza, estima social ou alguma forma de combinação global dessas necessidades? Wolff e De-Shalit ${ }^{36}$ ilustram com o exemplo da destinação de um coração para transplante: dois pacientes disputam um coração para transplante; a decisão será exclusivamente médica e destinará o coração para o paciente com maior risco de vida, ou analisará todo o perfil de "necessitado" do paciente? Algumas distopias no cinema apresentam esse cenário de decisão, sobretudo quando o planeta Terra, ameaçado de destruição, tem que escolher quem salvar num bunker. Em geral, cientistas, médicos e intelectuais aparecem nas listagens.

Segundo Wolff e De-Shalit, a prioridade comportará dois níveis, global ou setorial, dependendo do nível de decisão: global na definição geral de despesas de governo (educação, saúde, segurança etc.), e, no plano setorial (dentro da educação, dentro da saúde, dentro da segurança), será preponderantemente prioritária em favor dos mais necessitados, com outros elementos podendo entrar em causa. Aparentemente essa solução, com todas as suas dificuldades, parece refutar a objeção.

Ainda no campo da prioridade, reforça essa ideia a teoria das capacidades e das necessidades humanas básicas exposta por Amartya Sen ${ }^{37}$ e Martha Nussbaum ${ }^{38}$.

Segundo Martha Nussbaum ${ }^{39}$, cuja abordagem é inspirada na obra de Amartya Sen, as capacidades servem de índice para comparar o bem-estar entre diversos países (quais são, e em que intensidade, as capacidades que podem ser desenvolvidas em um certo país). Para Nussbaum, o argumento de Sen é superior ao dos utilitaristas e rawlsianos, pois não tem uma função apenas econométrica, como também estabelece uma teoria política sobre justiça social.

Nussbaum afirma que as capacidades representam o que uma pessoa é capaz de fazer ou de ser, em certo aspecto da vida. São um conjunto de oportunidades ou liberdades substanciais, pluralista a respeito dos valores. Nussbaum leva adiante esse conceito de Sen, estipulando uma lista das capacidades centrais e, além delas, identificando as capacidades internas - ou seja, as características de uma pessoa, que não são exatamente inatas, mas cujo desenvolvimento pode ser dependente do meio (por exemplo, nutrição na infância). As capacidades básicas, por seu turno, são as inatas cujo exercício se torna possível pelo desenvolvimento e treino. Essas capacidades podem ser combinadas com o contexto social, político e econômico, que pode favorecer ou não seu desenvolvimento ${ }^{40}$.

\footnotetext{
${ }^{36}$ WOLFF, Jonathan; DE-SHALIT, Avner. op. cit.

${ }^{37}$ SEN, Amartya. Desenvolvimento como liberdade. São Paulo: Companhia de Bolso, 1999.

${ }^{38}$ NUSSBAUM, Martha. The central capabilities. In: NUSSBAUM, Martha. Creating capabilities: the human development approach. Cambridge MA: Belknap Press of Harvard University Press, 2011. p. 17-45.

${ }^{39}$ Id. Ibid.

${ }^{40}$ Id. Ibid.
} 
Nussbaum destaca as capacidades em estágio funcional, que podem ser exercidas, porém não o são por decisão do agente. Quem está jejuando, por exemplo, tem a capacidade, mas não come porque não quer, não está em estágio funcional; quem não tem comida não tem sequer a possibilidade de ingressar num estágio funcional. Segundo a mesma autora, modelos de Estado podem diferir no modo como promovem essas capacidades. Para a autora, são centrais as seguintes capacidades, cuja implementação deve ser o objetivo de ordens políticas decentes: vida; saúde física; integridade corporal; sentidos, imaginação e pensamento; emoções; razão prática; afiliação; relações com outras espécies; jogo/brincar/lúdico; e controle sobre o ambiente político e material ${ }^{41}$.

Segundo Nussbaum ${ }^{42} \mathrm{e} \mathrm{Sen}{ }^{43}$, as capacidades não são fungíveis, de modo que a falta de uma pode ser compensada por outra. Há, no entanto, situações trágicas em que o agente tem que optar por exercer uma ou outra capacidade (ex: ter que parar de estudar para cuidar dos filhos). De acordo com Sen ${ }^{44}$, não há como fazer uma lista de preferências, embora Nussbaum ${ }^{45}$ entenda que, em alguns casos, fica evidente qual é a melhor solução.

$\mathrm{Na}$ teoria política polarizada por essa ideia de capacidades, é papel das instituições implementar condições mínimas, que podem decorrer do direito constitucional ou de seus princípios básicos. Trata-se, no entanto, uma teoria apenas parcial da justiça social, pois não resolve todos os problemas distribucionais. É o processo político ordinário que estabelecerá os níveis mínimos dessas capacidades.

A proposta de Nussbaum não está imune a críticas. Segundo Uyl e Rasmus$\operatorname{sen}^{46}$, o que é essencial para o bem do homem é a escolha e a voluntariedade; o âmbito político é o cenário da coerção e involuntariedade. Para os críticos de Nussbaum/ Sen, conjugar a busca de um bem com ação política é uma receita para controle político completo ${ }^{47}$. Não há limite para a coerção; então, a teoria de Nussbaum e Sen não é uma teoria liberal. Segundo os mesmos críticos, a visão de Nussbaum é hobbesiana: o Estado deve se ocupar das capacidades, desconsiderando o papel dos entes intermediários (escolas, igrejas, clubes, famílias etc.)

\footnotetext{
${ }^{41}$ NUSSBAUM, Martha. op. cit.

${ }^{42}$ Id. Ibid.

${ }^{43}$ SEN, Amartya. op. cit.

${ }^{44}$ Id. Ibid.

${ }^{45}$ NUSSBAUM, Martha. op. cit.

${ }^{46}$ DEN UYL, Douglas J.; RASMUSSEN, Douglas B. Liberalism in retreat. The Review of Metaphysics, v. 62, n. 4, p. 857-908, June 2009.

${ }^{47}$ Id. Ibid., p. 876.
} 


\section{0 critério de justiça libertarista}

A teoria da justiça de Nozick é amparada em uma teoria das titularidades na distribuição dos bens. Segundo Nozick, a distribuição dos bens na sociedade deve ser orientada por três princípios: (i) princípio da justiça na aquisição original da propriedade; (ii) princípio da justiça nas transferências; e, por fim, (iii) princípio de justiça na retificação das operações elaboradas em desconformidade com os dois primeiros princípios $^{48}$.

Conforme o autor libertarista, se a aquisição e as transferências forem justas, ou corrigidas posteriormente, todo resultado é justo também. Este é um princípio que ele chama de histórico, pois, para afirmar que um estado de coisas é justo, é preciso ver o "filme", e não apenas olhar uma determinada situação de fato em um dado momento, como em uma "fotografia". Nessa abordagem fotográfica (current time-slice principles of justice), tira-se uma foto da situação atual para avaliar se é compatível com algum princípio teleológico ou um fim.

Nesse particular, Nozick ${ }^{49}$ distancia-se de concepções de justiça que sustentariam alguma forma de redistribuição de bens ou serviços conforme um ideal pré-determinado. Naturalmente, um sistema de assistência ou seguridade social que implicasse redistribuição de bens cairia no defeito fundamental da injustiça, pois determinaria a distribuição de bens adquiridos de modo justo para terceiros.

Ao final da vida, numa obra-testamento ${ }^{50}$, Nozick revê algumas de suas posições, reconhecendo que alguns projetos humanos são, intrinsecamente, obras coletivas, dependendo da colaboração; porém, ele não indica se colocaria a prestação de serviços de saúde nesse cenário.

\section{Sistemas de saúde e teorias da justiça}

A primeira parte do trabalho não esgota, necessariamente, as modalidades contemporâneas de teoria da justiça, embora tenha sinalizado os principais critérios na distribuição de bens escassos. Para que se possam analisar os sistemas de saúde à luz de cada uma das teorias, é preciso estabelecer, ainda que provisoriamente, uma taxonomia de sistemas de saúde. A tarefa, no entanto, não é facilitada, sobretudo pela complexidade dos sistemas em curso atualmente. Na lição de Buss e Labra,

As instâncias de explicação dessa infinidade de fenômenos dependem muito mais do referencial analítico e da lente ideológica do pesquisador do que de leis inexoráveis do desenvolvimento dos sistemas de saúde. As dimensões do problema

\footnotetext{
${ }^{48}$ NOZICK, Robert. 'Distributive justice (excerpt)'. In: NOZICK, Robert (Ed.). Anarchy, State and Utopia. New York: Basic Books, Inc., 1974. p. 149-164.

${ }^{49}$ Id. Ibid.

${ }^{50}$ NOZICK, Robert. The examined life. New York: Touchstone, 1989. p. 17.
} 
refletem-se claramente nos estudos comparados na área da saúde: há crescente proliferação de tipologias que pretendem enquadrar com pouco êxito a diversidade existente; há grande dissenso quanto às variáveis determinantes das semelhanças e diferenças entre sistemas; tem sido escassa a contribuição que as análises comparativas têm dado para a construção de uma teoria mais geral das políticas, dos sistemas e das reformas na saúde, embora a contemporaneidade, marcada pela pluralidade, esteja talvez tornando obsoletas tais pretensões totalizantes ${ }^{51}$.

Uma tentativa de taxonomia poderia apontar para três cenários diferentes: em primeiro lugar, uma aposta no sistema de saúde universal e público, cabendo ao Estado as macrofunções de financiar, regular e prestar os serviços ${ }^{52}$; em segundo, ao contrário, um sistema em que a saúde estaria destinada ao mercado, não diferindo dos demais serviços e commodities à disposição para aquisição direta; e, em terceiro lugar, um sistema de seguros obrigatórios com contribuição de empregados e trabalhadores, cujo exemplo histórico mais evidente foi o sistema implantado por Bismarck, na Alemanha Imperial do século XIX ${ }^{53}$.

\section{Utilitarismo e sistemas de saúde}

Num plano mais amplo, certamente o argumento utilitarista favoreceria a concepção de um sistema de saúde centralizado, majoritariamente controlado pelo Estado nas funções de financiamento, regulação e prestação dos serviços de saúde. Em favor dessa conclusão, encontra-se a probabilidade de que a prestação centralizada resultaria numa economia de escala, sobretudo na compra de medicamentos e equipamentos destinados à prestação dos serviços. De outra parte, a centralização indicaria uma melhor alocação dos recursos naquelas esferas em que as informações coletadas indicassem serem mais necessários. Nesse cenário, então, a concepção de justiça utilitarista sinalizaria para um sistema público de saúde, não se descartando, no entanto, que o mesmo cálculo indicasse, em situação diversa, a possibilidade de um melhor resultado num sistema de predominância do mercado. Quer dizer, fixado o objetivo - por exemplo, melhoria dos índices gerais de saúde de uma certa população em data e local determinados -, não interessam para a concepção utilitarista os meios pelos quais se alcançaria tal objetivo.

\footnotetext{
${ }^{51}$ BUSS, Paulo M.; LABRA, María E. Sistemas de saúde continuidades e mudanças: Argentina, Brasil, Chile, Espanha, Estados Unidos, México e Québec. Rio de Janeiro: Fiocruz, 1995.

${ }^{52}$ MENDES, Eugênio Vilaça. Sistema Nacional de Saúde no Brasil: SUS e sistema complementar. Sanare Revista de Políticas Públicas, ano 3, n. 1, p. 97-103, 2002. Disponível em: <https://sanare.emnuvens.com. $\mathrm{br} /$ sanare/article/download/99/91>.

${ }^{53}$ DANELLI JUNIOR, César Augusto. 0 modelo alemão de seguridade social: evolução histórica a partir de Bismarck. RIDB, ano 2, n. 14, 2013.
} 
Além disso, superando a questão macro com a opção consistente por um sistema predominantemente público ou privado, o certo é que, na prestação final (na decisão entre como atribuir recursos escassos), o critério utilitarista poderia conduzir a conclusões pelo menos controvertidas. Ilustre-se, por exemplo, com os gastos vultosos com a saúde de idosos com expectativa de vida naturalmente menor que a dos demais cidadãos: utilitariamente, tais gastos não se justificariam, o que conduziria à decisão de investir os recursos escassos em pacientes com maior perspectiva de longevidade. Ou seja, atendendo-se ao critério utilitarista, seria alcançável uma economia de escala, porém com resultados nos casos individuais certamente difíceis de justificar.

\section{Igualitarismo e sistemas de saúde}

Sob uma inspiração igualitária, o sistema público de saúde seria orientado a uma prestação de atenção mínima, de mesma qualidade e atendendo a necessidades iguais. Esse sistema ignoraria necessidades particulares, determinadas por casos mais graves, e descartaria gastos excessivos em nome de uma universalização de atendimento. Naturalmente, ocorreriam situações de desamparo motivadas pela ausência de recursos, empregados para manter uma atenção geral e igual.

No exemplo de Pogge ${ }^{54}$, dos dois meninos, uma opção igualitarista determinaria simplesmente um nivelamento, sem atender às necessidades plenas de nenhum dos dois irmãos. Em homenagem à igualdade, nenhum teria uma consideração especial.

\section{Prioritarismo e sistemas de saúde}

Aplicado o critério da justiça do prioritarismo, as consequências seriam as opostas às do igualitarismo. Segundo o critério prioritarista, o justo seria, num primeiro momento, atender àquele em maior necessidade. No exemplo dos meninos, seria a família mudar-se para perto do hospital; no caso dos soldados no campo de batalha, mobilizar todos os recursos disponíveis para o soldado ferido com mais gravidade.

No cenário de um sistema de saúde, o prioritarismo determinaria o investimento mais intenso nas áreas que atendem aos casos de necessidade imediata. Essa opção, naturalmente, se daria em detrimento de um atendimento igual e generalizado.

Em certo sentido, a teoria da justiça de $R a w l s^{55}$, com seu princípio da diferença, orientaria a configuração de um sistema de saúde prioritário. Em breve síntese,

\footnotetext{
${ }^{54}$ POGGE, Thomas. World Poverty and Human Rights. Cambridge: Polity 2002. apud WOLFF, Jonathan; DESHALIT, Avner. op. cit.

${ }^{55}$ RAWLS, John. op. cit.
} 
o princípio da diferença determina que os bens e os recursos podem ser distribuídos de forma desigual, na medida em que essa desigualdade favorecer o grupo menos privilegiado. Essa elaboração, no entanto, focaliza a distribuição dos bens em geral, e não dos serviços de saúde. Aplicada a serviços de saúde, ou à saúde pública, o critério de Rawls poderia orientar o maior gasto para as pessoas mais necessitadas desses serviços, desde que em benefício de todos os demais. A título de exercício mental, seria necessário imaginar um cenário em que o atendimento a alguém com muita necessidade beneficiaria a todos os demais: imagine-se uma situação de grave crise de saúde pública em que fosse necessário atender, em primeiro lugar, aos profissionais da saúde (médicos, enfermeiros); essa prioridade - todos os recursos para salvar médicos e enfermeiros - estaria plenamente justificada pelo critério da prioridade, porém seria rechaçada pelo critério da igualdade.

\section{Libertarianismo e sistemas de saúde}

A perspectiva libertarista, ao contrário das anteriores, coloca em xeque a própria prestação de serviços públicos de saúde. Uma vez que a prestação de serviços financiados pelo Estado exigiria a captação de tributos e uma forma de redistribuição de renda, o próprio sistema público geraria uma situação de injustiça. Nessas condições, o justo seria um sistema de dominância de mercado absoluto, afastando-se o Estado de ações de saúde - ou ao menos daquelas que determinam a prestação de um serviço destacável e individualizado. As consequências da abstenção do Estado na prestação desses serviços seria, iniludivelmente, o deslocamento dos recursos e das decisões pessoais para os sistemas privados, com a consequente e esperada redução de seus custos causada pela concorrência. Aqui, evidentemente, a concorrência é o resultado esperado, porém não garantido, de uma dominância de mercado. Certamente, com o propósito de blindar seus interesses econômicos, os prestadores de serviços de saúde tenderiam à concentração, o que reclamaria intervenção pública para evitá-la - ação que, em si mesma, tem efeitos controvertidos.

\section{Considerações finais}

Este estudo ofereceu um elenco parcial de teorias contemporâneas da justiça e, em seguida, propôs a aplicação de seus postulados aos sistemas de saúde. O elenco não foi exaustivo, e muitas outras consequências poderiam ser extraídas de outras teorias da justiça, ou mesmo das já apresentadas, com maior aprofundamento. As teorias da justiça propõem soluções para a distribuição de bens escassos, aqui entendidos como os serviços de prestação de saúde.

A perfeita identificação das características das concepções de justiça utilitarista, igualitarista, prioritarista e libertarista permite uma análise mais precisa dos modelos ideais de saúde pública. 


\section{Referências}

ALEXANDER, Gregory; PEÑALVER, Eduardo M. An introduction to property theory. New York: Cambridge University Press, 2012.

BUSS, Paulo M.; LABRA, María E. Sistemas de saúde continuidades e mudanças: Argentina, Brasil, Chile, Espanha, Estados Unidos, México e Québec. Rio de Janeiro: Fiocruz, 1995.

DALRYMPLE, Theodore. Fairly just. In: DALRYMPLE, Theodore. Farewell fear. Nashville: New English Review Press, 2012.

DANELLI JUNIOR, César Augusto. O modelo alemão de seguridade social: evolução histórica a partir de Bismarck. RIDB, ano 2, n. 14, 2013.

DEN UYL, Douglas J.; RASMUSSEN, Douglas B. Liberalism in retreat. The Review of Metaphysics, v. 62, n. 4, p. 857-908, June 2009.

FRANKFURT, Harry G. Equality as a moral ideal. In: FRANKFURT, Harry G. The importance of what we care about. New York: Cambridge University Press, 1988f. p. 134-158.

KYMLICKA, Will. Filosofia política contemporânea. São Paulo: Martins Ed., 2006.

MENDES, Eugênio Vilaça. Sistema Nacional de Saúde no Brasil: SUS e sistema complementar. Sanare - Revista de Políticas Públicas, ano 3, n. 1, p. 97-103, 2002. Disponível em: <https:// sanare.emnuvens.com.br/sanare/article/download/99/91>.

MICHEL, Voltaire F. O princípio da diferença e o kantismo na teoria da justiça de John Rawls. Tese (Doutorado) - Faculdade de Direito, Universidade Federal do Rio Grande do Sul, Porto Alegre, 2007.

NAGEL, Thomas. Mortal question. Cambridge: Cambridge University Press, 1979.

NEDEL, José. A teoria ético-política de John Rawls: uma tentativa de integração de liberdade e igualdade. Porto Alegre: EDIPUCRS, 2000.

NOZICK, Robert. 'Distributive justice (excerpt)'. In: NOZICK, Robert (Ed.). Anarchy, State and Utopia. New York: Basic Books, Inc., 1974.

NOZICK, Robert. The examined life. New York: Touchstone, 1989.

NUSSBAUM, Martha. The central capabilities. In: NUSSBAUM, Martha. Creating capabilities: the human development approach. Cambridge MA: Belknap Press of Harvard University Press, 2011. p. 17-45.

PARFIT, Derek. Equality and priority. Ratio 10, p. 201-221, Dec. 1997.

POGGE, Thomas. World poverty and human rights. Cambridge: Polity, 2002.

RAWLS, John. Uma teoria da justiça. São Paulo: Martins Fontes, 2002. 
Teorias da justiça e saúde pública

SEN, Amartya. Desenvolvimento como liberdade. São Paulo: Companhia de Bolso, 1999.

SMART, J.C.C.; WILLIAMS, Bernard. Utilitarianism: for \& against. United Kingdom: Cambridge University Press, 1973.

WALDRON, Jeremy. Law and disagreement. New York: Oxford University Press, 1999.

WALZER, Michael. Spheres of justice: a defense of pluralism and equality. New York: Oxford University Press, 1983.

WOLFF, Jonathan; DE-SHALIT, Avner. Priority to the least advantaged. In: KYMLICKA, Will; MILLER, David (Eds.). Disadvantage. New York: Oxford University Press, 2007.

Voltaire de Freitas Michel - Doutor e mestre em Direito pela Universidade Federal do Rio Grande do Sul. Professor da IMED - Faculdade Meridional. Promotor de Justiça no Rio Grande do Sul. Porto Alegre/RS, Brasil.E-mail: voltairemichel@hotmail.com

Marc Antoni Deitos - Doutor em Direito pela Universidade Federal do Rio Grande do Sul (UFRGS); mestre em Relações Internacionais pela UFRGS. Diretor do Campus Porto Alegre da IMED - Faculdade Meridional. Porto Alegre/RS, Brasil.E-mail: marc.deitos@imed.edu.br 